\title{
The Bright and Dark Side of Altruism: Demographic, Personality Traits, and Disorders Associated with Altruism
}

\author{
Adrian Furnham • Luke Treglown • \\ Gillian Hyde • Geoff Trickey
}

Received: 9 July 2014/ Accepted: 15 October 2014/Published online: 28 October 2014

(C) The Author(s) 2014. This article is published with open access at Springerlink.com

\begin{abstract}
This study looked at personality trait and personality disorder correlates of self-rated altruism. In two studies over 4,000 adult British managers completed a battery of tests including a 'bright side' personality trait measure (HPI); a 'dark side'/disorders measure (HDS), and a measure of their Motives and Values which included Altruism. The two studies showed similar results revealing that those who were low on Adjustment (Neuroticism) but high on Interpersonal Sensitivity (Agreeableness), Prudence (Conscientiousness) and Inquisitiveness (Openness) were more likely to value Altruism and be motivated to commit altruistic acts which concerns helping others and creating an environment that places emphasis on customer service. Those more interested in "Getting Along" with others were more Altruistic than those more interested in "Getting Ahead" of others. Implications for the selection and management of altruistic people in a business are considered. Limitations and future directions of this research are also noted.
\end{abstract}

Keywords Altruism $\cdot$ Personality traits $\cdot$ Personality disorders

\footnotetext{
A. Furnham $(\bowtie) \cdot$ L. Treglown

Department of Clinical, Educational, and Health Psychology, University College London, London WC1H 0AP, UK e-mail: a.furnham@ucl.ac.uk

\section{A. Furnham}

BI Norwegian Business School, Nydalsveien 37, Oslo, Norway

G. Hyde - G. Trickey

PCL Tunbridge-Wells, Tunbridge Wells TN4 8AS, UK
}

\section{Introduction}

Altruism concerns behaviours an actor (an individual, group, or organisation) partakes in, at their own cost, in order provide benefit or increases the fitness of a recipient (Kerr et al. 2004; Oda et al. 2014). It can be defined a selfless exhibition of trading one's personal resources to benefit another. These traded resources can be of great importance and variety, with individuals sacrificing time, money, and organs for another (Ben-Ner and Kramer 2011).

Altruism could be defined as ethical doctrine where the moral value of an individual's actions depend solely on the impact on other individuals, regardless of the consequences on the individual itself. Ethically, altruism is often seen as a form of consequentialism, because it indicates that an action is ethically right if it brings good consequences to others. Altruism is similar, in some senses, to formal utilitarianism, which prescribes acts that maximise good consequences for all of society, while altruism prescribes maximising good consequences for everyone other than the actor.

There are also many philosophic debates about such things as whether human conduct can ever be genuinely altruistic and indeed whether it is always desirable (Pugmire 1978). Indeed it has also been suggested that "unfocused" corporate altruism can even be dangerous to those in need of assistance (Mitschow 2000).

It has been pointed out that often altruistic acts are promoted, and indeed made logistically possible, by organisations and institutions with a strong interest in producing them (Healy 2004). Writers have suggested that some organisations have begun to realise that promoting altruism as a corporate goal is beneficial and may indeed enhance overall organisational effectiveness (Kanungo and 
Conger 1993). Clearly, senior managers' personal values (which may include altruism) are potential drivers of corporate social responsibility.

Hemingway and Maclagan (2004) have suggested that a manager's corporate social responsibility can be described in two dimensions: motivational basis from altruistic to strategic and locus of responsibility from corporate to individual. They argue that individual manager's business ethics decisions are driven by their personal values and beliefs. They exhibit these values through the exercise of personal discretion and decision making particularly the allocation of resources. They argue for an emphasis on personal initiative to counter a tendency to view the corporation as the agent of business ethics. This study looks at various individual difference correlates of those who espouse the value of altruism. Indeed there is now an interest in leaders and managers attitudes and beliefs (i.e. Machiavellianism) and their moral behaviour at work (Sendjaya et al. 2014).

Altruism can also be considered as a corporate ethical value and studies have shown that career satisfaction mediates between corporate values and personal altruism at work (Valentine et al. 2011). However, it is quite possible that altruism could have negative consequences for an organisation particularly in family firms where decisions may be made more on the basis of biological ties than actual performance. It is quite possible that excessive altruistic citizenship behaviour over time could hurt and organisation indeed leading it to collapse.

But why do some people advocate and demonstrate altruism in their personal and social lives and others do not? This study looks at the "bright" and "dark" side correlates of self-reported altruism. By understanding the personality correlates of the altruistic individual at work it may be possible to identify those most likely to make unethical, immoral or selfish ethical decisions in corporate settings. The idea is that traits being more stable are the part drivers of values rather than the other way around. Correlational results do not provide evidence of causality though it is more likely that stable, biologically based traits shape motives and values which are less stable and open to modification and change (Furnham 2008).

In the literature, altruistic behaviours are either measured through an individual's self-reported likelihood of partaking in various scenarios (e.g. 'I have given money to charity'; Rushton et al. (1981), or recording actual behavioural responses (e.g. money donated to the other player in the dictator game (Camerer 2003)). Others have looked at the extent to which people say they value and are personally motivated to be altruistic. However, the results on personality correlates of different sorts of altruistic behaviours are not consistent from different studies. Bekkers (2006) found that high Openness and Extraversion led to more frequent charitable donation, whilst high Agreeableness was related to more frequent blood donation. Extraversion has been thought to influence altruism due to a desire for engaging with other individuals. Studies have indicated a moderate-to-weak, positive correlation between Extraversion and altruism (Ben-Ner and Kramer 2011; Oda et al. 2014). Swope et al. (2008), however, found no relation between personality correlates and amount given in an altruism game.

In a more recent study using the HEXACO model of personality, Aghababaei et al. (2014) found their prosocial personality test which is clearly a measure of altruism to be significantly correlated with all six major personality factors: Honesty-Humility, $r=.51$; Agreeableness, $r=.43$; Conscientiousness, $r=.38$, Openness, $r=.24$; Emotionality, $r=.22$ and Extraversion $r=.19$. Interestingly, the Dark Triad trait composite of Machiavellianism, narcissism and psychopathy was not a significant (negative) predictor as expected.

'Dark' side personality traits which are a manifestation of the personality disorders are also related to the probability of engaging in altruism. Thus, primary psychopathy and callousness have been shown to be uniquely and inversely related to altruism, whilst secondary psychopathy (when mediated by empathy) was inversely associated with altruism (White 2014).

Personality correlates seem to be more significant in explaining altruistic behaviours when the relationship between the actor and recipient is considered. Evolutionary perspectives outline specific drivers for different altruistic relationships. Altruism towards one's kin is motivated by the corollary of greatly increasing the chance of genetic survival, whilst non-relative altruism is an investment in the recipient to return the act in the future. Familial altruism fosters a 'kinship premium' (Curry et al. 2013), where altruism levels towards kin compared to non-relatives are significantly higher, even when social distance and emotional closeness are controlled for (Curry et al. 2013; Rachlin and Jones 2008). This issue is particularly relevant in family businesses (Boyd et al. 2013).

By investigating differing types of actor-recipient relationship, personality correlates of altruism become apparent. Ashton et al. (1998) found kin altruism to be facilitated by Emotional/Attachment personality constructs, which correlate significantly with high Agreeableness and low Emotional Stability. Non-relative/reciprocal altruism, however, has been associated with Forgiveness/Non-Retaliation constructs, which are correlated with high Agreeableness and Emotional Stability. In altruism towards 'collaborators' and 'competitors', Neuroticism has been found to positively affect giving, whilst a concave/U-curve (declining first, then increasing at higher levels) relationship was noted for Extraversion and Conscientiousness 
(Ben-Ner and Kramer 2011). Extraversion and Openness have been found to predict increased daily altruism towards friends and acquaintances, as well as strangers (Oda et al. 2014). Some research, however, found personality to play no role in giving to a kin, a result "consistent with the evolutionary view, that kin altruism is hard wired and strong, and therefore few individual differences will be observed in it." (Ben-Ner and Kramer 2011, p. 221).

\section{This Study}

In this study, we used the altruism scale from the motives, values, preferences inventory (MVPI) as the criterion (Hogan et al. 2007). The scale measures a desire to help others, a concern for the welfare of the less fortunate in life, and a lifestyle organised around public service and the betterment of humanity. According to the manual high scorers are perceived as honest, ethical, sympathetic and concerned about others. They have a need for nurturance which focuses on helping, protecting and caring for those in need in the workplace and other social settings. At work, those with altruistic motives appear to enjoy helping others, promoting staff morale, fostering open communications and trying to help their subordinates achieve greater engagement and advancement. On the other hand, low scorers are perceived as tough, uncommunicative and materialistic. According to the manual they tend to be assertive, confrontational, direct and outspoken (Hogan et al. 2007). Clearly, the more senior and powerful an individual at work is, the more influence they can exercise and the more important their values in establishing and maintaining corporate ethics (Hemingway and Maclagan 2004).

In this study, we looked a personality correlates of altruistic values. The "bright side" traits were measured using the Hogan Personality Inventory (Hogan et al. 2007). The HPI consists of 206 items that are used to produce seven personality traits and six criterion scores. The seven personality traits are: Adjustment (Neuroticism); Ambition (Leadership and Status Seeking); Sociability (Extraversion); Interpersonal Sensitivity: (Agreeableness); Prudence (Conscientiousness); Inquisitive (Openness); Learning Approach (Need for Intellectual Stimulation) (Hogan et al. 2007). Based on the previous literature, we predict $(\mathrm{H} 1)$ Interpersonal Sensitivity which is essentially a measure of Agreeableness would be most strongly and positively correlated with altruism. This is based on the findings of Aghababaei et al. (2014) and Ashton et al. (1998).

This study used the Hogan Developmental Survey now extensively used in organisational research and practice to measure "dark side" personality disorders in the "normal population'. The HDS focuses only on the core construct of each disorder from a dimensional perspective (Hogan and Hogan 2001, p. 41). Various relatively studies have used the HDS and have shown it to be a robust, reliable and valid instrument (Furnham and Trickey 2011; Furnham et al. 2013). It should be noted that these personality disorders are grouped along different axes or different clusters. When clustering three are usually made: A: Odd/Eccentric (Paranoid, Schizoid, Schizotypal); B: Dramatic/Emotional/Erratic (Antisocial, Borderline, Histrionic, Narcissistic) and C: Anxious/Fearful (Avoidant, Dependent and Obsessive-Compulsive). These three clusters have also been described as Moving Against Others (by deliberately manipulating and controlling others) Moving Toward Others (by building alliances with others) and Moving Away From others (by maintaining their distance and pushing others away (Hogan et al. 2007).

There is little data or theorising in this area to formulate hypotheses though it was predicted that the Moving Away Traits: Excitable (H2) Sceptical (H3), and Reserved (H3) would be negatively correlated with Altruism, while the Moving Toward traits, Diligent (H4) and Dutiful (H5) would be positively related to Altruism. This is based on the work of Furnham et al. (2014) who showed that people who had this profile were attracted to more traditional jobs and institutions which upheld high moral and pro-social values.

\section{Method}

Participants

Study 1 There were a total of 1,458 participants of whom 874 were males and 584 females. Their mean age was 36.14 years $(\mathrm{SD}=12.90$ years). They were all middle to senior managers of various British and European organisations.

Study 2 There were a total of 2,548 participants of whom 1,744 were males and 884 females. Their mean age was 40.16 years $(\mathrm{SD}=16.33$ years $)$. They were also all middle to senior managers assessed for selection, development and promotion.

Measures

1. Values The MVPI (Hogan et al. 2007) measures 10 Motives/Preferences. Each scale is composed of five themes: (a) lifestyles, which concern the manner in which a person would like to live, (b) beliefs, which involve 'shoulds', ideals and ultimate life goals, (c) occupational Preferences, which include the work 
an individual would like to do, what constitutes a good job, and preferred work materials, (d) aversions, which reflect attitudes and behaviours that are either disliked or distressing, and (e) preferred Associates, which include the kind of persons desired as coworkers and friends. MVPI scores are quite stable over time, with test-retest reliabilities ranging between .64 and .88 (mean $=.79)$. More than 100 validation studies have been conducted on the MVPI with results indicating that the inventory is effective in predicting job performance and outcome variables such as turnover (Hogan Assessment Systems; Tulsa, USA). In this study, we focus exclusively on the value of altruism.

2. Dark Side Traits Hogan Development Survey (Hogan et al. 2007) is a measure of the personality disorders expressed in non-clinical language. The survey includes 154 items, scored for 11 scales, each grouping 14 items. Respondents are requested to 'agree' or 'disagree' with the items. The HDS has been crossvalidated with the MMPI personality disorder scales. It has considerable evidence of satisfactory reliability and validity (Fico et al. 2000; Hogan and Hogan 2001). Furnham and Crump (2005) show the overlap of the HDS and DSM-IV disorder terminology. There are good British norms for this measure (Furnham and Trickey 2011) and it has been used in various recent studies (Furnham et al. 2012, 2013, 2014).

3. Personality Hogan Personality Inventory (Hogan et al. 2007) is a measure of normal personality functioning closely aligned to the Big Five. It measures seven dimensions of personality adjustment, ambition, sociability, interpersonal sensitivity, prudence, inquisitive and learning approach. It was initially developed in 1976. It has 7 domains and 41 facets measured by 206 items. It has impressive evidence of reliability and validity and used in many studies (Hogan et al. 2007).

\section{Procedure}

Data for study 1 and study 2 were obtained from two consultancies. In the first study, participants completed the tests online before attending either training or coaching sessions where they were given full feedback on their test results. In the second study, participants were required to attend a middle management assessment centre where they completed the questionnaires. The assessment was aimed at determining the suitability of each manager for promotion. Each manager was given feedback on the results, including how he/she related to the test norms as well as his/her colleagues.

\section{Results}

Correlations and Factor Analyses

Table 1 shows the correlational results between Altruism and the seven Bright Side factors for both studies. The results were consistent and indicated that five of the seven factors were significantly positively correlated to Altruism particularly Interpersonal Sensitivity (also known as Agreeableness). Factor analysis also confirmed that for both analyses a two factor model emerged identical to Digman's (1997) Alpha (Communion) and Beta (Agency) model where the former comprises Agreeableness (Interpersonal Sensitivity), Conscientiousness (Prudence) and Neuroticism (Adjustment), and the latter Extraversion (Ambition and Sociability) and Openness (Inquisitive and Learning Approach).

Table 2 shows the correlational results for Altruism and the eleven Dark Side factors for both studies. The results were reasonably consistent and indicated that three scales (Excitable, Sceptical, and Reserved) were negatively, and four scales (Colourful, Imaginative, Diligent, Dutiful) positively, correlated with Altruism. Factor analysis of the eleven factors yielded the well-replicated three-fold structure entitled Moving Away, Moving Against and Moving Toward others.

\section{Regressions}

Table 3 shows the results of two identical regressions for sample 1 and 2. For both, the criterion variable was the Altruism score. In a step-wise regression first age and sex were entered, then social desirability, then the seven Bright Side factors. Results were similar for both analyses. Older females tended to have higher scores and those factors accounted for 3-4\% of the variance. The consistent findings for the bright side traits indicated the more highly people score on Interpersonal Sensitivity, Inquisitiveness and Prudence, and the lower they score on Adjustment, the more altruistic they were. Personality factors accounted for around $17 \%$ of the variance.

This regression was repeated but this time using the "higher-order" alpha-beta model. Study 1 was significant $\left(F(5,1452)=39.05, p<.001, \operatorname{Adj} R^{2}=.12\right)$ and indicated both factors significant predictors Alpha: (Beta $=.18$, $t=-7.13, p<.001)$ and Beta (Beta $=.14, t=5.39$, $p<.001)$. The results for the second study were slightly different $\left(F(5,2563)=51.55, p<.001\right.$, Adj $\left.R^{2}=.09\right)$ and indicated two predictors Alpha $($ Beta $=.10, t=4.67$, $p<.001)$ and Beta (Beta $=.19, t=9.53, p<.001)$.

Table 4 shows the two regressions for the eleven dark side factors. Gender and social desirability were significant in both regression showing females with higher social 


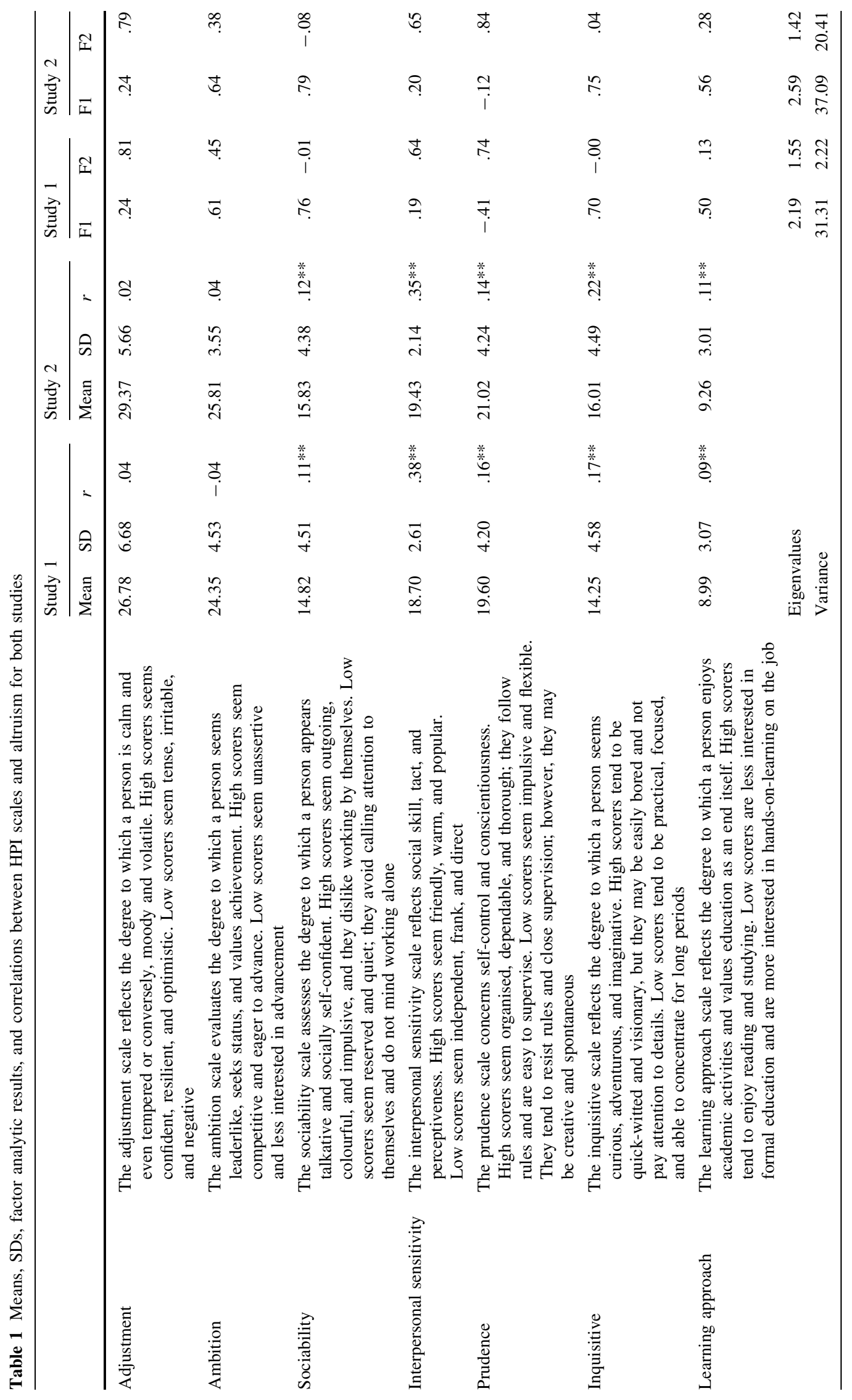




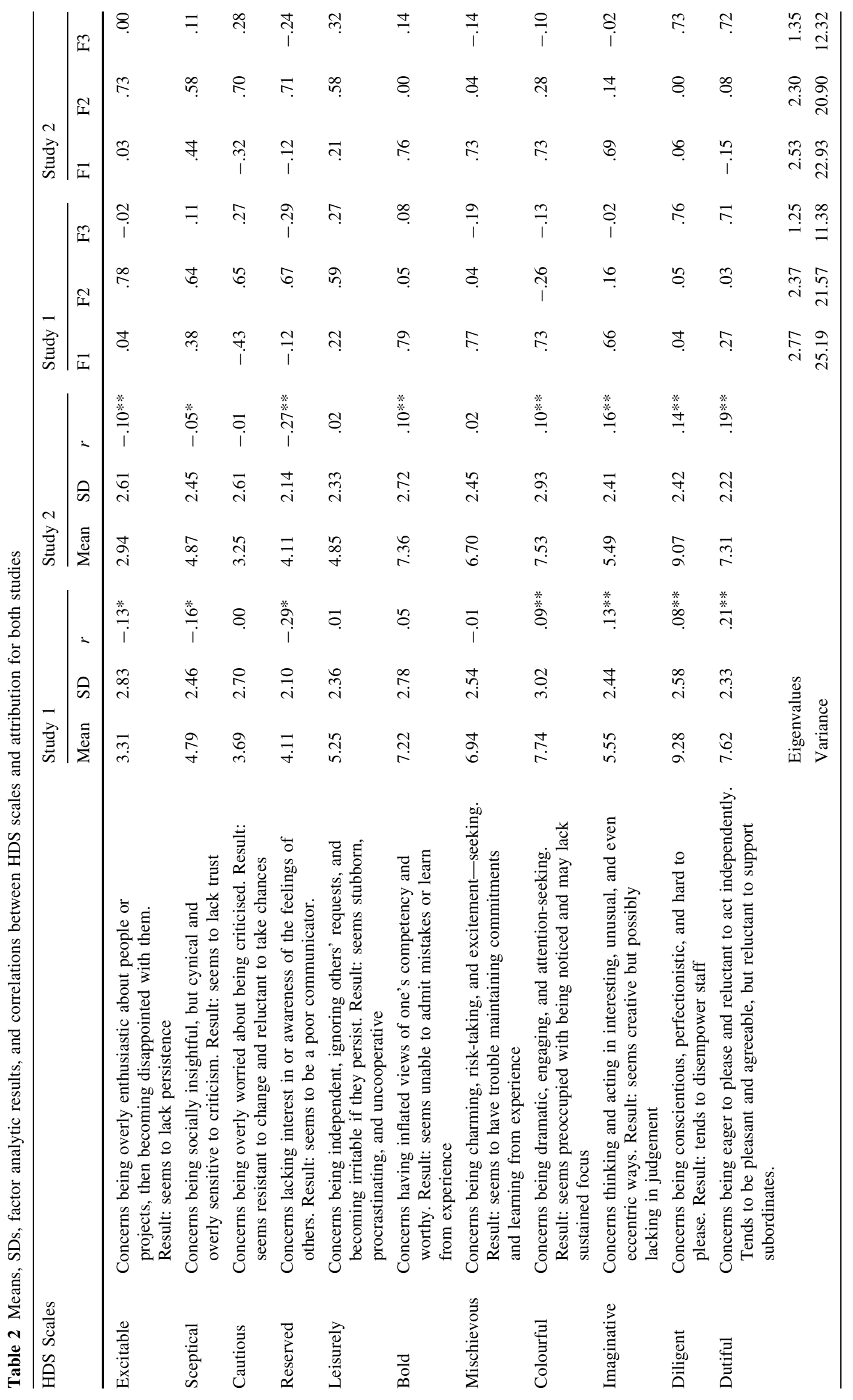


Table 3 Results for the regression using the HPI for both studies

$* * * p<.001 ; * * p<.01 ;$

$* p<.05$

Table 4 Results for the regression using the HDS for both studies

\begin{tabular}{|c|c|c|c|c|}
\hline & \multicolumn{2}{|l|}{ Study 1} & \multicolumn{2}{|l|}{ Study 2} \\
\hline & Beta & $t$ & Beta & $t$ \\
\hline Age & .07 & $2.83 * *$ & .06 & $3.38 * *$ \\
\hline Gender & .17 & $6.64 * *$ & .14 & $7.36^{* * *}$ \\
\hline SD & .10 & $4.21 * * *$ & .04 & 1.93 \\
\hline Adjustment & -.07 & $2.37 * *$ & -.15 & $6.83 * * *$ \\
\hline Ambition & -.09 & $3.22 * * *$ & -.02 & .90 \\
\hline Sociability & .03 & 0.99 & .00 & .21 \\
\hline Interpersonal sens & .37 & $11.98 * * *$ & .34 & $16.45^{* * *}$ \\
\hline Prudence & .12 & $4.21 * * *$ & .11 & $5.49 * * *$ \\
\hline Inquisitive & .20 & $7.39 * * *$ & .23 & $11.43 * *$ \\
\hline \multirow[t]{4}{*}{ Learning approach } & .06 & $2.52 * *$ & .06 & 1.13 \\
\hline & $F(2,1455)=34.38 * * *$ & $\operatorname{Adj} R^{2}=.04$ & $F(2,2566)=34.60 * * *$ & Adj $R^{2}=.03$ \\
\hline & $F(3,1454)=29.63 * * *$ & $\operatorname{Adj} R^{2}=.06$ & $F(2,2565)=39.63 * * *$ & $\operatorname{Adj} R^{2}=.04$ \\
\hline & $F(10,1447)=44.61 * * *$ & $\operatorname{Adj} R^{2}=.23$ & $F(9,2559)=74.90^{* * *}$ & Adj $R^{2}=.21$ \\
\hline
\end{tabular}

\begin{tabular}{|c|c|c|c|c|}
\hline & \multicolumn{2}{|l|}{ Study 1} & \multicolumn{2}{|l|}{ Study 2} \\
\hline & Beta & $t$ & Beta & $t$ \\
\hline Age & .05 & $2.11 *$ & .03 & 1.35 \\
\hline Gender & .15 & $6.01 * * *$ & .13 & $6.19 * * *$ \\
\hline SD & .15 & $5.78 * * *$ & .07 & $3.43 * * *$ \\
\hline Excitable & -.11 & $3.68 * * *$ & -.08 & $3.27 * * *$ \\
\hline Sceptical & -.14 & $4.78 * * *$ & -.03 & 1.28 \\
\hline Cautious & .06 & 1.90 & .05 & 1.88 \\
\hline Reserved & -.23 & $8.22 * * *$ & -.22 & $9.73 * * *$ \\
\hline Leisurely & .05 & 1.78 & .04 & 1.62 \\
\hline Bold & .05 & 1.47 & .04 & 1.47 \\
\hline Mischievous & -.03 & 1.05 & -.03 & 1.39 \\
\hline Colourful & .02 & .02 & .03 & 1.10 \\
\hline Imaginative & .17 & $6.21 * * *$ & .19 & $8.24 * * *$ \\
\hline Diligent & .04 & 1.39 & .08 & $3.69 * * *$ \\
\hline \multirow[t]{4}{*}{ Dutiful } & .14 & $5.08 * * *$ & .15 & $6.99 * * *$ \\
\hline & $F(2,1455)=34.38 * * *$ & $\operatorname{Adj} R^{2}=.05$ & $F(2,2280)=32.14 * * *$ & Adj $R^{2}=.03$ \\
\hline & $F(3,1454)=29.63^{* * *}$ & $\operatorname{Adj} R^{2}=.05$ & $F(3,2279)=36.48 * * *$ & Adj $R^{2}=.05$ \\
\hline & $F(14,1443)=27.06^{* * *}$ & $\operatorname{Adj} R^{2}=.20$ & $F(14,2268)=34.74 * * *$ & $\operatorname{Adj} R^{2}=.17$ \\
\hline
\end{tabular}

$* * * p<.001 ; * * p<.01 ;$

$* p<.05$ $p<.001)$ and Moving Toward (Beta $=.20, t=7.88$, $p<.001)$. In sample 2 , the regression was also significant $\left(F(6,2276)=50.20, p<.001\right.$, Adj $\left.R^{2}=.12\right)$. All three higher-order factors were predictive: Moving Away (Beta $=-.14, \quad t=6.47, \quad p<.001)$; Moving Against $($ Beta $=.17, t=8.52, p<.001)$ and Moving Toward $($ Beta $=.20, t=9.68, p<.001)$.

Finally, two step-wise regressions were run, one for each study with altruism as the criterion. First gender and age were entered, followed by social desirability and then the five higher order factors from both the HPI and HDS. 
This was significant for study $1(F(8,1449)=31.57$, $p<.001$, Adj $\left.R^{2}=.15\right)$. All five factors were significant: Alpha $($ Beta $=.10, t=2.73, p<.001)$, Beta $($ Beta $=.09$, $t=2.64, p<.01$ ), Moving Away (Beta $=-.11, t=2.76$, $p<.01)$, Moving Against (Beta $=.08, t=2.29, p<.04)$ and Moving Toward (Beta $=.18, t=18, p<.001)$. The regression was also significant for study $2(F(8,2274)=$ $43.41, p<.001, \operatorname{Adj} R^{2}=.13$ ). Four of the five higher order factors were significant: Alpha (Beta $=.10, t=3.43$, $p<.001)$, Beta (Beta $=.15, t=5.32, p<.001)$; Moving Against $($ Beta $=.10, t=3.82, p<.001)$ and Moving Toward $($ Beta $=.18, t=8.42, p<.001)$.

\section{Discussion}

The main aim of this study was to try to see which "bright" and "dark" side traits were related to altruism and how much variance they might account for. The first study showed that whilst five of the seven bright side traits were positively associated with altruism it was two in particular that were most strongly correlated.

It is hardly surprising that Interpersonal Sensitivity (or Agreeableness) was the strongest correlate. Indeed in some models like the NEO-PI-R, Altruism is a facet of Agreeableness along with such things as trust, straightforwardness, compliance, modesty and tender-mindedness (McCrae and Costa 2010). Low scorers are described as guarded, cynical, sceptical, competitive, conceited and hard-hearted. It is interesting, however, that leaders and managers with low, rather than high, Agreeableness scores seem to be more successful at work (Furnham 2008) possibly because of their ability to confront poor performance and make tough decisions.

It is also interesting that it was only one of the two Extraversion dimensions, namely Sociability (but not ambition) which was related to altruism. This may in part explain the equivocal findings from previous studies namely precisely how Extraversion was measured. It also provides support for the Hogan et al. (2007) notion of splitting the more achievement oriented aspect of extraversion (Surgency) from the outgoing sociable facet. Sociable people find that altruism is beneficial in establishing and maintaining relationships at work and elsewhere.

The second most important correlate was Inquisitiveness, which equated with Openness. Why should inquisitive people be more altruistic? It maybe that they are more curious about people, more attentive to their inner feelings and more psychological healthy and mature. This may make them more finely attuned to those around them and more cognizant of the belief that "what goes around comes around" in the sense that altruistic acts tend to be returned.
It could also be evidence of a tendency to see the "bigger picture" and to be aware of various potential implications of actions that translates into an ability to see the general good in altruistic behaviours (Kanungo and Conger 1993). However, this finding requires replication and further investigation.

The regressions shown in Table 3 show that personality factors accounted for around a fifth of the variance, after controlling for demography (age and sex) and social desirability (dissimulation). The results indicated that Adjustment (i.e. Neuroticism) was associated with Altruism indicating that those low on adjustment tended to be less altruistic. It is possible that it takes some confidence to be altruistic believing that people would both like and accept offers of help. Those low on Adjustment may be too pessimistic and self-obsessed to be able to regularly offer help to others. There is evidence that some people with this profile have a "well I never got any help so I'm not helping them" approach, thus not seeing the benefit of reciprocal altruistic actions.

The "dark" side analysis was particularly interesting because this seems to have never before been explored. The results were mainly, but not always, in the predicted direction. Thus, both correlation and regression results in both studies suggest that two disorders are negatively (Excitable, Reserved) and two positively (Imaginative and Dutiful) related to Altruism. Excitable people are those with Borderline symptoms which suggest they are highly moody and unstable very much "blowing hot and then cold" toward people. Their disappointment and distrust of others probably explains their low Altruism. Reserved people, who are essentially Schizoid, also report low Altruism because they take little interest in other people and tend to shun them. Whilst it is no surprise that Dutiful people (Dependent Personality Disorder), who are eager to please express more Altruism, it is less clear why those who are Imaginative (Schizotypal Personality Disorder) also are more Altruistic unless they find it particularly interesting. It could be a lack of cynicism and general curiosity in Imaginative people.

Table 2 shows the eleven dark side traits factored as always into groups labelled Moving Away, Moving Against and Moving Toward others. The regression showed, as may be expected that Moving Away was negatively, and Moving Towards positively, related to being Altruistic. However, it seemed less obvious that Moving Against was positively related to altruism. Indeed the correlations indicated that Colourful (Histrionic Personality Disorder) in both studies and Bold (Narcissistic Personality Disorder) in one study was positively correlated with the measure of Altruism. There could be various explanations for this: first, that Moving Against people might assume they are altruistic, whereas they are not. Second, that 
superficially (false) altruism may seem to be a manifestation of manipulativeness because it is not sincere. Indeed Kauten and Barry (2014) provided supportive evidence of this when they showed that narcissists self-reports showed that they were altruistic, but that peer-reports showed that they were not. Further work needs to explore personality correlates of altruistic beliefs and behaviours.

What are the implications of this study for business ethics? Whilst not all organisations would either profess to be altruistic in some sense (with respect to various shareholders) or indeed value altruism (which could be seen as expensive and counter-productive) it is a personal value of some people that drives their decision making (Hemingway and Maclagan 2004). It has also been suggested that people's values determine their choice of organisation as well as their behaviour in them (Furnham et al. 2014). This study has demonstrated clear personality trait and disorder correlates of altruism. Thus, it may be expected that people with a particular profile are likely to be more or less altruistic to others at work. This profile could be used in selection and development contexts to identify those more or less likely to be altruistic.

This study had one very obvious limitation which concerned the data collection method. It was based entirely on self-report which is not ideal. Although we had a measure of social desirability to try to control for impression management and dissimulation, we accept that it is possible some of the results may have been inflated because of various biases. As in all of these studies, it would have been desirable to have both a multi-faceted observer-based and objective measure of altruism as the criterion score.

Future studies in personality, personal values and business ethics may consider how traits and disorders are linked to ethical and unethical beliefs and behaviours via personal motives and values. It seems clear that certain traits are clearly and logically linked to a more caring attitude to all others (stakeholders) and that these could serve as a useful way to identify individuals more suited to certain jobs. It would also be interesting to attempt to categorise or profile an organisations espoused corporate values using tests, like the MVPI, that are designed to assess those of individuals.

Open Access This article is distributed under the terms of the Creative Commons Attribution License which permits any use, distribution, and reproduction in any medium, provided the original author(s) and the source are credited.

\section{References}

Aghababaei, N., Mohammadtabar, S., \& Saffarinia, M. (2014). Dirty Dozen versus the $\mathrm{H}$ factor: Comparison of the Dark Triad and Honesty-Humility in prosociality, religiosity and happiness. Personality and Individual Differences, 67, 6-10.
Ashton, M. C., Paunonen, S. V., Helmes, E., \& Jackson, D. N. (1998). Kin altruism, reciprocal altruism, and the big five personality factors. Evolution and Human Behaviour, 19, $243-255$.

Bekkers, R. (2006). Traditional and health-related philanthropy: The role of resources and personality. Social Psychology Quarterly, 69, 349-366.

Ben-Ner, A., \& Kramer, A. (2011). Personality and altruism in the dictator game: Relationship to giving to kin, collaborators, competitors, and neutrals. Personality and Individual Differences, 51, 216-221.

Boyd, D., Halfond, J., Johnson, P., \& Kainen, T. (2013). A family affair: A case of altruism or aggrandisement? Journal of Business Ethics, 113, 157-161.

Camerer, C. F. (2003). Behavioral game theory: Experiments in strategic interaction. Princeton: Princeton University Press.

Curry, O., Roberts, S. G. B., \& Dunbar, R. I. M. (2013). Altruism in social networks: Evidence for a 'kinship premium'. British Journal of Psychology, 104, 283-295.

Digman, J. (1997). Higher-order factors of the Big Five. Journal of Personality and Social Psychology, 73, 1246-1256.

Fico, J., Hogan, R., \& Hogan, J. (2000). Interpersonal compass manual and interpretation guide. Tulsa, OK: Hogan Assessment Systems.

Furnham, A. (2008). Personality and intelligence at work. London: Routledge.

Furnham, A., \& Crump, J. (2005). Personality traits, types and disorders. European Journal of Personality, 19, 167-184.

Furnham, A., Hyde, G., \& Trickey, G. (2012). Bright aspects to dark side traits. Personality and Individual Differences, 52, 908-913.

Furnham, A., Hyde, G., \& Trickey, G. (2013). Do your dark side traits fit? Dysfunctional personalities in different work sectors. Applied Psychology (in press).

Furnham, A., Hyde, G., \& Trickey, G. (2014). The dark side of career preference: Dark side traits, motives and values. Journal of Applied Social Psychology, 44, 106-114.

Furnham, A., \& Trickey, G. (2011). Sex differences in the dark side traits. Personality and Individual Differences, 50, 517-522.

Healy, K. (2004). Altruism as an organizational problem. American Sociological Review, 69, 387-404.

Hemingway, C., \& Maclagan, P. (2004). Managers' personal values as drivers or corporate social responsibility. Journal of Business Ethics, 50, 33-44.

Hogan, R., \& Hogan, J. (2001). Assessing leadership: A view from the dark side. International Journal of Selection and Assessment, 9, 40-51.

Hogan, R., Hogan, J., \& Warrenfeltz, R. (2007). The Hogan guide. Tulsa, OK: Hogan Press.

Kanungo, R., \& Conger, J. (1993). Promoting altruism as a corporate goal. Academy of Management Journal, 7, 37-49.

Kauten, R., \& Barry, C. (2014). Do you think I'm as kind as I do? Personality and Individual Differences, 61, 69-73.

Kerr, B., Godfrey-Smith, P., \& Feldman, M. W. (2004). What is altruism? Trends in Ecology and Evolution, 19, 135-140.

McCrae, R., \& Costa, P. (2010). NEO inventories. Florida, PAR: Odessa.

Mitschow, M. (2000). Unfocused altruism. Journal of Business Ethics, 23, 73-82.

Oda, R., Machii, W., Takagi, S., Kato, Y., Takeda, M., Kiyonari, T., et al. (2014). Personality and altruism in daily life. Personality and Individual Differences, 56, 206-209.

Pugmire, D. (1978). Altruism and ethics. American Philosophical Quarterly, 15, 75-79.

Rachlin, H., \& Jones, B. A. (2008). Altruism among relatives and non-relatives. Behavioural Processes, 79, 120-123. 
Rushton, J., Chrisjohn, R., \& Fekken, G. (1981). The altruistic personality and the self-report altruism scale. Personality and Individual Differences, 2, 293-302.

Sendjaya, S., Pekerti, A., Hartel, C., Hirst, G., \& Butarbutar, I. (2014). Are authentic leaders always moral? Journal of Business Ethics, $1-15$.

Swope, K. J., Cadigan, J., Schmitt, P. M., \& Shupp, R. (2008). Personality preferences in laboratory economics experiments. Journal of Socio-Economics, 37, 998-1009.
Valentine, S., Godkin, L., Fleischman, G., Kidwell, R., \& Page, K. (2011). Corporate ethical values and altruism. Journal of Business Ethics, 101, 509-523.

White, B. A. (2014). Who cares when nobody is watching? Psychopathic traits and empathy in prosocial behaviours. Personality and Individual Differences, 56, 116-121. 